\title{
MULHERES NA PERIFERIA \\ DO URBANISMO: \\ INFORMALIDADE SUBORDINADA, AUTONOMIA DESARTICULADA E RESISTÊNCIA \\ em Mumbai, São Paulo e Durban
}

\section{WOMEN ON THE PERIPHERY OF URBANISM:}

SUBORDINATE INFORMALITY, DISARTICULATED AUTONOMY AND RESISTANCE IN SÁO PAULO, MUMBAI AND DURBAN

\author{
Luciana Fukimoto Itikawa \\ Universidade de São Paulo, Instituto de Estudos Brasileiros, São Paulo, São Paulo, Brasil
}

R E S U M O : A informalidade subordinada e a autonomia desarticulada são duas faces da mesma moeda: não há neutralidade na posição que a informalidade ocupa na periferia do capitalismo. Parece impossível, portanto, a transição automática do informal para o formal, uma vez que a informalidade funciona como reserva de braços e de terras por subacumulação e superacumulação. Subacumulação, porque só resta o trabalho compulsório por sobrevivência. Superacumulação, porque são extraídos, além dos direitos trabalhistas, todo o aparato para a reprodução social da força de trabalho, incluindo o território que os trabalhadores informais ocupam. Há uma clara assimetria decisória e de riqueza como reflexo de relaçóes desiguais de poder e subordinação, como as discriminaçôes de gênero, raça, casta e classe em São Paulo, Durban e Mumbai. As experiências de resistência de mulheres trabalhadoras informais domiciliares e ambulantes nessas metrópoles revelam contradiçóes e inovaçôes nos arranjos de organização e de articulação com movimentos sociais urbanos, assim como são exemplos de conquistas parciais e pontuais.

P A L A V R A S - C H A V E : gênero; espaço urbano; resistência; subordinação; autonomia.

A B S T R A C T : Subordinate informality and disarticulated autonomy are two sides of the same coin: there is no neutrality in the position that informality occupies on the periphery of capitalism. Therefore, an automatic transition from informal to formal seems impossible, since the role of informality is to act as a supply of physical force and of lands by sub-accumulation and super-accumulation. Sub-accumulation-because there is only compulsory work to survive. Super-accumulation - because not only are the labor rights removed, but also all the apparatus for the social reproduction of the labor force, including the territory that the workers occupy. There is a clear asymmetry between decisions and wealth, as a result of the unequal relations of power and subordination, such as gender, race, caste and class discrimination in the three metropolises: São Paulo, Mumbai and Durban. These experiences of resistance by these informal, home-based or street-vending working women reveal contradictions and innovations in the organization and connection with social urban movements, as well as in their partial and isolated achievements.

K E Y W O R D S : gender; urban space; resistance; subordination; autonomy.

DOI: http://dx.doi.org/10.22296/2317-1529.2016v18n1p57 
A carne mais barata do mercado é a carne negra

que vai de graça pro presídio

e para debaixo de plástico

que vai de graça pro subemprego

e pros hospitais psiquiátricos

mas mesmo assim

ainda guardo o direito

de algum antepassado da cor

brigar sutilmente por respeito

brigar bravamente por respeito

brigar por justiça e por respeito

de algum antepassado da cor

brigar, brigar, brigar

A Carne Mais Barata do Mercado é a Carne Negra

Compositores: Seu Jorge, Marcelo Yuca e Wilson Capellette

\section{TRABALHO, MULHER E TERRA NA PERIFERIA DO CAPITALISMO: SÃO PAULO, MUMBAI E DURBAN}

Elza Soares canta: "A carne mais barata do mercado é a carne negra". Poderíamos acrescentar: a carne mais barata do mercado também é a carne periférica, feminina e sem-terra.

O ano de 2015 terminou com agendas políticas muito contundentes, porém, nem todas inéditas: direitos da mulher, à educação, ao trabalho, à terra, à cidade etc. Ocupar os espaços - públicos e privados - como resistência à máquina de remover direitos é a estratégia dos movimentos urbanos e rurais de ontem e de hoje. Entretanto, algumas dessas agendas se destacaram, sobretudo, pela presença frequente de lideranças mulheres, pela autoria cada vez mais jovem das reivindicaçôes, bem como pela astúcia em desvelar novos interesses que estavam por detrás dos velhos processos. 2016, então, continua com o desafio da articulação da transversalidade da exclusão.

Maricato (1995) apontou as estruturas domésticas que sustentam a manutençâo da exclusão territorial e as características da periferização. Rolnik (2015), 20 anos depois, mostra as engrenagens excludentes, locais e mundiais, cada vez mais sofisticadas na periferia global.

Apesar da influência de fluxos, fusóes e da volatilidade de capitais nacionais e internacionais sobre processos domésticos de segregação espacial, curiosamente, ao nos debruçarmos sobre os contextos das metrópoles de São Paulo/Brasil, Mumbai/ Índia e Durban/África do Sul, o binômio terra-trabalho continua sendo uma das senhas para remoção forçada. No Brasil, entre as várias reflexôes sobre a periferia do capitalismo, antes mesmo da questão espacial desvelada por Maricato, já havia uma larga tradição nos estudos brasileiros sobre o papel do barateamento do trabalho e de sua articulação com o regime fundiário. Os formatos se modificaram, mas a estratégia conjugada e excludente, não: trabalho escravo e senzala (FREYRE, 1997); 
abolição da escravatura e Lei de Terras (MARICATO, 1997); trabalho de imigrantes e regime de colonato (BARBOSA, 2008); trabalho registrado operário e favela autoconstruída (OLIVEIRA, 2003); trabalho precário terceirizado/informal e ocupações (ITIKAWA, 2015b).

Se no período colonial brasileiro a escravidáo significava a retirada do fator trabalho da reprodução do capital, através da não remuneração, da restrição da liberdade e da mercantilização da figura do trabalhador, hoje há artifícios bem mais sutis e complexos: terceirização, trabalho forçado, empreendedorismo no domicílio etc. Não é à toa que os movimentos de moradia, ao perceberem como os efeitos desse golpe no direito ao trabalho reverberam no direito à cidade, protestaram contra a Lei n. ${ }^{\circ}$ 4330/2004, chamada de Lei da Terceirização em 2015 (ITIKAWA, 2015a).

Os mecanismos verificados nas três metrópoles estudadas, infelizmente, não são diferentes: o barateamento da reprodução da força de trabalho não garante acesso universal a salário, habitação, transporte, licença-maternidade etc. São semelhantes nas engrenagens; entretanto, se diferenciam nas estatísticas e nas camadas a mais de exclusão por casta, raça e gênero. Apesar da difícil tentativa de entender o que aproxima a metrópole de Sáo Paulo das diferentes complexidades das outras duas, um dos objetivos desta pesquisa é entender processos de remoção forçada, paralelos aos movimentos de resistência de mulheres em São Paulo, Mumbai e Durban. Neste artigo, são enunciados exemplos emblemáticos de remoção forçada de espaços públicos e privados urbanos de trabalhadores informais em cada uma das três metrópoles, bem como de movimentos de resistência protagonizados por mulheres que uniram as questóes de gênero, urbano e trabalho precário informal.

Este artigo é um breve resumo da primeira etapa de uma pesquisa de pós-doutorado no Instituto de Estudos Brasileiros da Universidade de São Paulo, publicada em 2015 no formato de livro. A pesquisa obteve suporte do Conselho Latino-americano de Ciências Sociais (CLACSO), através do edital de cooperação tricontinental sul-sul 2014-2015.

Essa primeira etapa da pesquisa foi um estudo comparativo baseado nas seguintes frentes: i) cruzamento da literatura sobre trabalho, urbano e movimentos de resistência de mulheres nos três países; ii) aplicação de 10 entrevistas em profundidade a trabalhadoras informais brasileiras que moram em habitações precárias nas cidades de São Paulo e um grupo focal com seis indianas em Mumbai no ano de 2015. No município de São Paulo, foram escolhidas trabalhadoras informais não só das periferias norte, sul, leste e oeste, como também trabalhadoras de cortiços e ocupaçôes do centro da cidade. Em Mumbai, o grupo focal aconteceu em Dharavi, a maior favela da Índia. De forma resumida, as entrevistas focaram questôes do tripé gênero-trabalho informal-urbano a partir dos seguintes recortes: i) divisão sexual do trabalho produtivo/reprodutivo e voz dos sujeitos; ii) local, jornada e relaçóes de trabalho; iii) titularidade, deslocamentos diários casa-trabalho, acesso a infraestruturas, locais de moradia e trabalho em 20 anos.

A segunda etapa da pesquisa, em 2016, terá mais entrevistas e a espacialização, na Região Metropolitana de Sáo Paulo, dos dados do Censo de 2010, da Relação Anual de Informaçóes Sociais (RAIS) 2015 e da Pesquisa de Mobilidade 2012 do Metrô SP, com a finalidade de investigar as especificidades e precariedades territoriais do trabalho informal feminino. Entre as hipóteses que serão trabalhadas na segunda 
10 termo modernização conservadora foi melhor desenvolvido por Tavares e Fiori (1993). etapa estão: trabalhadoras informais têm menos titularidade da casa e do terreno; têm menor ou pior acesso às infraestruturas urbanas; moram e se mudam de periferia para periferia; perdem mais tempo nos deslocamentos diários; ocupam posiçóes subordinadas ou náo no trabalho produtivo e nos movimentos sociais organizados etc.

Este artigo analisa duas condiçóes laborais emblemáticas da exclusão conjugadas no binômio terra-trabalho: subcontratação e autonomia, em dois ambientes de trabalho, domiciliar e na rua (ambulante). O objetivo é verificar se há manutenção da subordinação ou desarticulação econômica nas questôes de gênero, relaçôes de trabalho e espaço urbano na informalidade ou se, ao contrário, há exemplos de políticas e açốes que contradigam esse padrão.

Em primeiro lugar, são brevemente apresentados e contextualizados os padróes de segregação e segmentação dos mercados de trabalho nos três países e seus efeitos sobre as respectivas metrópoles. Os exemplos dados mostram as condiçóes ambivalentes de subordinação na informalidade e a autonomia econômica desarticulada da produção de riqueza. Apesar das três metrópoles conterem contradições e polarizaçôes típicas dos países do capitalismo periférico, cada uma delas manifesta a segregação socioespacial diferentemente, segundo recortes de gênero, raça e etnia.

Em seguida, é explicitado como o processo de urbanização nos três países, em vez de desafiar a herança de exclusão social, reproduziu-a e deu-lhe conformaçóes de ilegalidade estrutural na terra e baixíssima qualidade urbanística. A industrialização, com baixos salários e empregos insuficientes, revelou-se uma modernização conservadora $^{1}$ ao excluir grande parcela dos assalariados formais e informais do direito à cidade.

Por fim, diante dos processos excludentes no trabalho e no espaço urbano, são apresentadas, com seus respectivos avanços, estagnaçôes e retrocessos, algumas açóes de resistência de movimentos sociais nas três metrópoles. Em cada uma delas, o binômio desarticulação/subordinação é desafiado por iniciativas coletivas de resistência, seja na forma de movimentos encabeçados pelas próprias trabalhadoras, seja por meio da articulação de organizações e instituições que lhes dão apoio.

\section{MERCADO DE TRABALHO: SEGREgAÇÃo E SEgMENTAÇÃo WAY OF LIFE}

O processo de industrialização no Brasil, Índia e África do Sul - e também em outros países na periferia do capitalismo - produziu contingentes de trabalhadores que não tiveram lugar nas relaçôes formais regulamentadas. As raízes do trabalho subcontratado e por conta própria são tão profundas na formação dos mercados de trabalho nos três países que é possível perguntar se estas náo são exatamente as modalidades de trabalho que os diferencia dos países de pleno emprego.

As engrenagens da estrutura produtiva e do mercado de trabalho na periferia do capitalismo são formatadas de modo que o acesso à mundializaçáo capitalista seja seletivo e subordinado. Essa segregaçáo permite que os países centrais do capitalismo detenham os conhecimentos técnicos e científicos, sequestrados em patentes e submetidos a um regime de obsolescência acelerada. À periferia resta, do ponto de vista da produção da riqueza, com diferentes nuances setoriais e diferenças entre os países, a dependência tecnológica e a inserção subordinada na divisão internacional do trabalho. Essa divisão pressiona os sistemas produtivos nacionais, intensificando a competitividade, enfraquecendo o trabalho organizado e limitando a ação pública. 
Isso restringe os efeitos multiplicadores de investimento e enfraquece o impacto potencial das políticas sociais e trabalhistas.

Países do capitalismo periférico como o Brasil, a Índia e a África do Sul guardam semelhanças na manutenção histórica das anomalias no emprego, na perspectiva ortodoxa da sociologia do trabalho. Centro e periferia, desse modo, fazem parte de uma mesma totalidade, que se manifesta com dinâmicas estruturais orgânicas. A liberalização e a diversificação das economias industriais periféricas não só expandiram as atividades informais, mas também as tornaram mais diversas. Entretanto, mesmo com o aumento da participação do setor industrial, não há transformação da estrutura ocupacional segmentada e segregada (BARBOSA, 2008). Nesse sentido, a informalidade não é uma falha a ser consertada. Também não é somente um subproduto da globalização das cadeias de valor, da divisão internacional do trabalho e das sucessivas crises internacionais do capitalismo.

Estar na periferia, por sua vez, não significa apenas estar espacialmente distante da concentração das infraestruturas urbanas e do direito à cidade. As várias periferias tratadas aqui estão relacionadas à localizaçáo ambivalente entre a conquista textual de direitos e a manutenção da prática da exclusão, da precariedade e da dependência do acesso a esses mesmos direitos.

Para Pochmann (2008), países periféricos como o Brasil atualizam antigas e permanentes características do trabalho para a sobrevivência, por meio do crescimento horizontalizado de serviços como autogestão da própria sobrevivência. Para o autor, $31 \%$ dos trabalhadores que iniciaram um empreendimento o fizeram pela impossibilidade de encontrar um novo emprego: são proprietários de pequenos negócios de baixa produtividade, náo geram lucro, apenas garantem o próprio sustento e de sua família.

O Brasil passou, nos últimos dez anos, por mudanças profundas na estrutura da sociedade brasileira e no mercado de trabalho, resultado dos esforços de articulação de diferentes setores progressistas no sentido da redemocratização e da inclusão social. Apesar de as políticas macroeconômicas terem contribuído para a elevação do salário real, a competição internacional e as intensas pressóes do setor privado e de parte da burocracia do setor público ainda mantêm uma tendência no sentido oposto: flexibilização e terceirização da força de trabalho. Segundo dados da Pesquisa Nacional de Amostras por Domicílios (PNAD) do Instituto Brasileiro de Geografia e Estatística (IBGE), em 2012, o Brasil apresentava uma grande diversidade de inserçôes ocupacionais. A informalidade, de acordo com a PNAD, somou 42\%, em 2013 (IBGE, 2014).

$\mathrm{Na}$ Índia, o crescimento, concentrado em uma pequena elite de poucas famílias e negócios, estendeu-se, no máximo, a uma pequena parcela da classe média urbana (BARBOSA et al., 2015). Um dos resultados foi 1 milhão de novos milionários e mais 56 milhôes de pobres durante o boom (DAVIS, 2006). A segregação no mercado de trabalho indiano é aguda, porque, além das questôes de gênero, sobrepóem-se hierarquias de casta, etnia e religião (UNNI, 2008). Ao contrário do Brasil, a Índia, nos últimos anos, investiu, sobretudo, em programas de combate às injustiças do sistema de castas, os quais não foram suficientemente abrangentes (CACCIAMALI, 2014). A economia informal é quase a totalidade das ocupaçôes no país: 93\% (CHEN; RAVEENDRAN, 2014). Nesse sentido, o mercado de trabalho formal na Índia é ínfimo, uma verdadeira exceção. 
2 Coloured, na África do Sul, é a denominação para o que equivale a mestiços ou pardos no Brasil (RACE, 2012).
$\mathrm{Na}$ África do Sul, historicamente, o acesso às oportunidades de emprego era baseado em um sistema hierárquico dividido entre quatro categorias raciais: brancos, coloured $^{2}$, indianos e negros. Com exceção dos brancos, coloured, indianos e negros sofriam restriçôes ao acesso à capacitação a certas profissóes, ao direito de abrir e estabelecer negócios, bem como ao tipo de mercadoria que poderia ser vendida. Apesar de a economia sul-africana ter crescido 5\% entre 2001 e 2007, ela foi abalada imensamente pela crise econômica, com aumento da taxa de desemprego de 30\% em 2009 e 33,2\% em 2011 (BHORAT et al., 2013). Em 2009, 67\% dos trabalhadores na África do Sul estavam na informalidade (YU, 2010).

A superação da dependência econômica por meio do trabalho feminino produtivo não extinguiu a posição subordinada nas relações de gênero no trabalho, a qual atravessa, incólume, os contextos do trabalho formal e informal dos três países. As análises sobre divisão sexual e segmentação ocupacional, segundo critérios de gênero, por sua vez, sugerem subordinação com diferentes graus e especificidades no Brasil, Índia e África do Sul (ABRAMO, 2007; UNNI, 2008; SKINNER, 2009).

\section{INFORMALIDADE SUBORDINADA E AUTONOMIA DESARTICULADA}

Apesar da heterogeneidade das relações econômicas e de trabalho na informalidade, a hipótese apresentada neste artigo avança sobre o lugar desta última na periferia do capitalismo. Uma visão dualista da economia entende que o informal pode ser compreendido a partir da mesma matriz evolucionista da economia dos países do centro do capitalismo. Nessa visão, a economia informal existiria e persistiria porque o crescimento econômico ou o desenvolvimento industrial falharam. Essa visão subsidia a crença de que o crescimento da economia e da indústria, a capacitaçáo para o mercado de trabalho, o microempreendedorismo, a adequação do marco regulatório, entre outros, são elementos estruturais da transição para a economia formal (INTERNATIONAL LABOUR OFFICE, 2015).

Entretanto, tais políticas não têm sido suficientes para enfrentar a dimensão e as violaçôes da informalidade, seja porque não há interesse na incorporação do custo da reprodução da força de trabalho, seja porque não é equalizada a assimetria decisória (ITIKAWA, 2015b). A penetração, truncada e parcial, das relaçôes capitalistas de produção, a não generalização das relaçôes salariais e a consolidação da dependência tecnológica externa são componentes da incapacidade histórica dos países da periferia do capitalismo para alterar essa racionalidade.

Nesse sentido, com a manutenção da assimetria de poder econômico entre trabalho formal e informal, mesmo com a institucionalidade da autonomia no trabalho e da conquista da propriedade dos meios de produção pelas/os trabalhadoras/es informais, ainda são perpetuadas as ambivalências entre, por exemplo, regimes de inclusão no sistema tributário e exclusão dos direitos sociais. Veremos, para os casos das três metrópoles, que a matriz evolucionista é funcional na sustentação de programas governamentais e não governamentais, porém ela é de alcance curto, residual e pontual.

A subordinação clássica, da forma como é entendida nas relaçóes salariais, continua acontecendo na informalidade, mesmo com a desvinculação da relação contratual, do ambiente de trabalho e da pessoalidade. A informalidade subordinada é, portanto, a estratégia do capital para reduzir os custos do trabalho e dar primazia a 
uma nova ordem entre capital-trabalho: manutenção do controle, sem a responsabilização com a reprodução da força de trabalho.

Além disso, ao não eliminar a subordinação, essa estratégia de informalização do trabalho pende ainda mais a favor do capital: baixíssima remuneração por peça produzida; formas diferentes de controle do tempo e da produção, a partir de novos dispositivos de monitoramento e estabelecimento de metas; transferência dos riscos do negócio aos informais; extensão da jornada através da indistinção entre tempo de trabalho e de não trabalho etc. (ABÍLIO, 2011).

A informalidade é considerada, para instituiçôes como o Banco Mundial e o Fundo Monetário Internacional (FMI), adequada ao discurso de amortecimento em tempos de crise econômica. É vista como adaptável ao regime flexível, natural às mulheres, ao conjugar trabalho produtivo e reprodutivo. Contudo, na prática, a flexibilidade, especificamente nas ocupaçóes femininas, é mais uma outra camada de subordinação e superacumulação. Segundo Davis (2006), a flexibilidade exigida em redes de produção e de distribuição faz uso, em larga escala, do trabalho feminino desqualificado, desprotegido e de baixa remuneração.

O trabalho por conta própria e autônomo precário, por sua vez, não está articulado ao setor moderno da economia: a existência dele está relacionada diretamente à provisão de geração de renda na parcela excedente do mercado de trabalho, devido à não generalização da relação salarial (BARBOSA, 2008). Abílio (2011) fala na ficção real da acumulação financeira do trabalhador informal. A ideologia do microempreendedorismo tem um entendimento isolado da geração de renda autônoma, vista como uma virtude e uma modernização das relaçóes de trabalho, mas sem incluir a reprodução social do/a trabalhador/a. Essa compreensão do significado do trabalho por conta própria e autônomo é decisiva para contrariar políticas públicas que defendem o empreendedorismo, divulgado com a aparência virtuosa de independência dos trabalhadores.

Nesse sentido, os efeitos negativos do trabalhador por conta própria como excedente da força de trabalho acabam desdobrando-se para todo o mercado de trabalho, uma vez que atuam exercendo forte pressão sobre a faixa de salários, rebaixando-a, bem como sobre a rotatividade no emprego formal ${ }^{3}$, aumentando-a (KREIN, 2006).

Apesar da existência concreta de políticas de formalização direcionadas às/aos trabalhadoras/es por conta própria, elas não estão atreladas à articulação produtiva ao longo das cadeias locais de valor nem têm o objetivo de fortalecer trabalhadores e organizá-los visando à negociação coletiva e ao acesso aos mercados. Considerando isso, pode-se afirmar que a condição da informalidade no trabalho rebaixa as esperanças de mobilidade social vertical, há, no máximo, "mobilidades laterais" (TELLES, 2006).

As políticas governamentais direcionadas às/aos trabalhadoras/es por conta própria estão encerradas na lógica individual e competitiva, baseada na sobrevivência, na acumulação e reprodução isolada, sem enraizamento social e articulação de classe. No caso brasileiro, o programa Microempreendedor Individual (MEI) tem foco tributário e de proteção social individual. Não há qualquer formação de um espírito crítico nem a construção de arranjos produtivos que promovam alternativas à mercantilização das trocas através da articulação e do protagonismo das/os trabalhadoras/es (ALCÂNTARA et al., 2013)

\footnotetext{
3 Segundo o autor, o Brasil possui um dos maiores índices de rotatividade do mundo: o volume de dispensas representa aproximadamente $60 \%$ do estoque de emprego formal. Dessas dispensas, 2/3 ocorrem com trabalhadores com menos de 1 ano de emprego e 1/3, com menos de 3 meses.
} 


\section{O RAPTO DO TERRITÓRIO DO TRABALHO}

Historicamente, a relação entre exclusão da terra e dificuldade de inserção no mercado de trabalho mantém-se indissociável. As barreiras para ultrapassá-la estão na entrada ou no interior das estruturas fundiárias e do mercado de trabalho.

A acumulaçáo na periferia do capitalismo, ao menos da forma como se desenvolveu nas três metrópoles, não se deu apenas por sua reprodução ampliada no território, desafiando fronteiras e ocupando novos espaços, mas também por despossessão. Aqui, entendemos acumulação por despossessão de acordo com o conceito atribuído por Harvey (2005) ao regime de acumulação capitalista movido à expulsão e apropriação: extinçâo de direitos trabalhistas e políticas de bem-estar social; remoçóes de populaçôes urbanas; desapossamento de bens, incluindo desvalorização por fusôes e aquisiçôes e também os novos mecanismos como despossessão de direitos de propriedade intelectual, roubo de recursos genéticos, apropriação da cultura popular etc.

Considerando que a terra tem sido posta na dianteira como um importante ativo financeiro, as/os trabalhadoras/es informais que ocupam o espaço urbano, público ou privado, ficam vulneráveis à disputa dos interesses do setor imobiliário e do próprio Poder Público.

A literatura sobre os processos de remoçóes forçadas de trabalhadoras/es de espaços públicos e privados nas três metrópoles demonstra que eles/as, ao serem expulsos/ as e retirados/as da base territorial de trabalho, perdem suas conexóes de trabalho. Essas conexôes envolvem relaçóes com fornecedores, clientes, auxiliares, intermediários, bem como todas as articulaçóes e dinâmicas entre trabalho e moradia, trabalho e família, trabalho e redes de sociabilidade.

As investigações acadêmicas sobre movimentos de resistência, juntamente das entrevistas realizadas durante esta pesquisa, permitem afirmar que a falta de um lugar legalizado na cidade e no emprego formal não fazem das/os trabalhadoras/es produtoras/es passivas/os do espaço urbano. Tanto as/os trabalhadoras/es ambulantes quanto as/os domiciliares tiram proveito do vigor e do dinamismo dos espaços que

4 Sem a titularidade da terra, conforme desenvolvemos adiante. escolhem, ainda que os ocupem informalmente ${ }^{4}$.

Para as/os ambulantes, dois aspectos demonstram a precariedade no acesso à terra: i) a licença provisória ou permanente de ocupaçáo do espaço público, em geral, é revogável pelo Poder Público, de forma unilateral; ii) o exercício da atividade em áreas valorizadas, sujeitas a projetos urbanísticos, megaeventos e operaçóes imobiliárias excludentes, significa que há uma maior probabilidade de expulsão para a periferia. Já em relação às/aos trabalhadoras/es domiciliares, são três ônus territoriais: i) alto custo da terra, que resulta na precariedade da habitabilidade (cortiços, favelas, ocupaçóes) e da posse do imóvel; ii) obrigação, como estratégia de reduzir os custos, de sobrepor moradia ao trabalho (com reflexos na indistinção espacial entre trabalho e família); iii) responsabilidade pelos deslocamentos para compra de insumos e canalização das mercadorias, sendo os pesos do tempo e do dinheiro descontados da produtividade. 


\section{GESTÃo DA EXCEÇÃo}

As três metrópoles estudadas demonstram estar em franca transformação territorial, social e econômica. Nelas, contudo, continua sendo seletiva a forma pela qual grupos sociais sistematicamente à margem dos direitos acessam determinados recursos escassos. Como a perspectiva de integrá-los é cada vez mais frágil, essas geometrias, além de compulsórias, são complexas, dada a heterogeneidade dos atores e seus arranjos.

Parte da literatura denomina esse tipo de acesso aos direitos, isto é, mediado e seletivo, de "gestáo da exceção". Segundo Misse (2002), trata-se de um mercado da cidadania que funciona por meio de mercadorias políticas que são ofertadas por vários agentes em troca de direitos. Entre os direitos fornecidos seletivamente, estão: licença no espaço público, em troca de voto ou dinheiro; assessoria jurídica, em troca de conversão religiosa; unidades habitacionais, em troca de prioridade no acesso etc.

Essa "gestão da exceção" é construída por redes de sociabilidade nas periferias para garantir questóes mínimas de sobrevivência. As redes de mediação comunitária funcionam a partir tanto de arranjos específicos de organização da própria populaçẫo, com algumas hierarquias internas, quanto da atuação do Estado, de organizaçôes não governamentais (ONGs) ou de agências multilaterais. Segundo Marfaing e Thiel (2015), elas têm o papel de integrar determinadas redes de sobrevivência em redes de acumulação, por meio do acesso privilegiado aos mercados. Os agentes se posicionam como interlocutores com fornecedores ou financiadores importantes, ou seja, mobilizam esferas de influência. A ambivalência entre dependência e autonomia no acesso a direitos apareceu na literatura sobre remoçóes forçadas nas três metrópoles e também nas entrevistadas feitas em São Paulo e no grupo focal conduzido em Mumbai.

\section{AS MULHERES NAS VÁRIAS PERIFERIAS: SUBORDINAÇÃO, AUTONOMIA E RESISTÊNCIA EM SÃO PAULO, MUMBAI E DURBAN}

Em São Paulo, são apresentados casos da região central e sul (Jabaquara), em Mumbai, do norte (Dharavi), e, em Durban, do centro (Warwick). Nessas cidades, para a viabilização de novas possíveis fronteiras imobiliárias, os governos locais adiantaram-se, promovendo um verdadeiro processo de limpeza social, isto é, de retirada da cena urbana de todos os grupos que impliquem um cenário de popularização ou pobreza.

As três metrópoles estudadas apresentam movimentos surgidos no interior de grupos que desenvolveram processos de resistência ante as frentes de remoção urbana, retirada de direitos, inibição da voz e deslegitimação da representatividade. As açôes dsses movimentos não necessariamente redundaram em conquistas; entretanto, eles são resultados de diferentes iniciativas contra-hegemônicas que desafiam as engrenagens e as sobreposições de exclusão e subordinação. Alguns deles são formados exclusivamente por mulheres e têm diferentes abrangências territoriais, tempos de existência e alcances nas conquistas.

Algumas das experiências desafiam formas de transgressão da norma patriarcal 
e subordinadora das relaçóes de gênero nesses espaços. Elas são projetos coletivos que parecem escapar dos limites da dominação, tutela e exploração, indo na direção da afirmação de uma identidade livre. Náo obstante, do ponto de vista das conquistas das condiçôes de trabalho, não está claro se existe uma autorregulação libertadora sobre o tempo e o lugar do exercício da informalidade ou, em lugar disso, um aprofundamento da precarização da jornada e do ambiente de trabalho.

Os processos de resistência colhidos das metrópoles, os quais reverberam nos seus respectivos países e regiôes, demonstram que não há linearidade e tampouco homogeneidade entre as experiências examinadas. De qualquer forma, o critério de escolha deles fundamentou-se na ideia de que são iniciativas que têm em comum o fato de terem surgido a partir da base dos grupos de trabalhadoras/es, ou seja, foram reaçôes espontâneas, cujos fortalecimento e organização originaram-se no interior dos grupos, ainda que estes tenham recebido suporte e apoio externos.

Resistência é aqui compreendida com base em dois princípios. Por um lado, ela é vista como reposição do conflito, em meio à fabricação de consensos que teimam em negar a existência da exclusão e da subordinação; e, por outro, como potência, isto é, como consciência e negação da humildade ou servidão que tanto agrada às elites (SCHWARZ, 2012).

\section{SÃo PAULO: PLANALTO dE OPORTUNIDADES SELETIVAS E A INSUBORDINAÇÃO DAS PERIFERIAS}

Até a década de 2000, algumas matrizes de estudos urbanos apresentavam a Região Metropolitana de Sáo Paulo (RMSP) a partir da dualidade entre centro e periferia, baseada na concentração/desconcentração gradual de urbanizaçáa, emprego, equipamentos públicos, etc. que ia do centro, com melhor oferta, para a periferia homogênea e sem infraestrutura urbana (BÓGUS; TASCHNER, 1999). Posteriormente, a RMSP passou a ser vislumbrada como um território diversificado e crescentemente heterogêneo em seus indicadores urbanos e sociais, com nuances no recorte de renda e segregador por raça e classe nos bairros de predominância de brancos e renda alta (MARQUES, 2015). A relação centro-periferia deixou de ser dual para ser complexa e mútipla.

Da mesma forma, assim como há heterogeneidade nas estruturas urbanas, igualmente diversificadas são as relaçôes de trabalho e como elas se manifestam no território da RMSP. A mutiplicidade das relaçóes de emprego, do trabalho independente (autônomo, conta-própria, etc.) e a participação significativa do trabalho informal na estrutura do mercado de trabalho também acontecem com distribuição desigual na metrópole paulistana (PAMPLONA, 2013).

Duas manifestaçóes da informalidade são apresentadas neste artigo: a primeira, o emprego ilegal subcontratado, quando o trabalhador é autônomo, porém subordinado a uma empresa; e a segunda, o trabalho independente por conta-própria para o público, o ambulante. A subordinação na subcontratação do trabalho informal se dá, por exemplo, na imposição unilateral do regime das encomendas e reflete a assimetria decisória sobre a produção. Nesse contexto, o/a trabalhador/a informal é avisado/a do prazo de entrega com poucas semanas ou dias de antecedência. A seguir, são oferecidos três representativos exemplos das diferenças nas dinâmicas de subcontratação: o primeiro é o caso de uma pequena empresa de vestuário; o segundo, de uma grande 
multinacional da confecção; e o terceiro, de um órgão público.

O primeiro exemplo, como assinalado, é de uma loja do vestuário de pequeno porte localizada no centro da cidade de São Paulo. Essa loja, segundo os dados, estipulava o preço da peça, entregava os tecidos cortados e a peça piloto para ser copiada nas peças que seriam entregues. $\mathrm{O}$ valor da peça era de $\mathrm{R} \$ 1,00$, por trabalhador, e, para o dono da oficina, de $\mathrm{R} \$ 3,80$, por peça (PYL, 2012). A loja ainda cobrava multas, caso não fossem costuradas as etiquetas ( $10 \%$ de desconto) ou se as peças apresentassem defeitos ( $20 \%$ de desconto). Os trabalhadores eram imigrantes latinos que viviam em São Paulo e recebiam, por mês, $\mathrm{R} \$ 350,00$, ou seja, menos da metade do salário mínimo brasileiro. Até 2011, apenas o dono da oficina possuía cidadania regularizada.

O segundo exemplo envolve a multinacional de confecçôes Zara, cujo trabalho foi tipificado como "análogo à escravidão". Nesse regime de subordinação, além da reprodução de graves precariedades e de ter características de trabalho forçado (servidão por dívida, jornadas extenuantes etc.), o grau de controle do contratante em relação à oficina de costura é algo que o distingue. Um representante da empresa intermediária passava até o final de semana e as últimas madrugadas acompanhando o trabalho dentro da oficina, a fim de assegurar que as roupas fossem entregues (CGGDH, 2012).

O terceiro exemplo, envolvendo um órgão público na subcontratação, mostra que essa estratégia de redução dos custos do trabalho é utilizada, indiscriminadamente, até mesmo por instituiçóes que deveriam zelar pela conformidade dos direitos. As peças do vestuário tinham como destinação o Instituto Brasileiro de Geografia e Estatística (IBGE), pois tratava-se de coletes para recenseadores (PYL; HASHIZUME, 2010). O episódio é revelador de um processo de superacumulação: uma empresa de confecçáo venceu o processo licitatório, cujo pregão eletrônico partiu do valor $\mathrm{R} \$ 52,34$ e diminuiu para $\mathrm{R} \$ 18,70$. Para produzir o lote de 51 mil coletes, a empresa de confecção subcontratou uma firma não legalizada, a qual receberia $\mathrm{R} \$ 5,00$ por colete produzido. Tal firma, por sua vez, subcontratou uma oficina de trabalhadores bolivianos, que receberiam $\mathrm{R} \$ 1,80$ por peça, ou seja, quase 30 vezes menos do valor inicial do pregão.

$\mathrm{O}$ contexto de outra categoria de trabalhador informal, os ambulantes, não foge à regra da assimetria decisória e precariedade das condiçóes de trabalho. Ao ocupar o espaço público sem a devida licença para o exercício do comércio ou para a prestação de serviços, eles são obrigados a enfrentar ao menos duas situações: fuga da repressão diária, não rara e com o uso da violência; negociação, econômica ou política, da permanência no espaço público. A licença, como "mercadoria rara", passa a ser, assim, uma moeda de troca valiosa, negociada por meio de disputas, nas quais o que vale é a influência política que tal sindicato, associação ou o próprio trabalhador tem em relação ao Poder Público (ITIKAWA, 2006). Além de o/a trabalhador/a estar subordinado/a aos agentes do Estado na legalidade ou ilegalidade, ele/a também é refém de lideranças que se tornam chefes de territórios ao concentrarem as negociaçóes com o Poder Público e estipularem regras arbitrárias sobre os/as demais moradores/as ou trabalhadores/as.

Nesse sentido, a modificação dos atributos espaciais pelos trabalhadores informais não acontece somente na mercantilização da terra urbana (aluguel da licença, por exemplo), mas também na divisão do espaço, loteando-o segundo regras específicas de poder. Existe uma delimitação de áreas de influência de lideranças de trabalhadores destinadas à venda organizada, que funciona dentro de uma hierarquia 
específica de distribuição, comercialização e comunicação (ITIKAWA, 2006).

Outro aspecto é a corrupção como instrumento da gestão da exceção. Devido ao abismo do número irrisório de licenças, $1,4 \%$ em relação ao número total de trabalhadoras/es, há um mercado ilegal para que seja feita vista grossa a certa ocupação clandestina do espaço público. Historicamente, o esquema de corrupçáo permaneceu, sucessivamente, nas diferentes gestôes municipais, chegando a movimentar, em 2002, cerca de $\mathrm{R} \$ 1$ milhão, por mês, de arrecadação de propina de trabalhadores ambulantes pelos agentes fiscais no centro de São Paulo. A soma não só impressiona pela dimensão dos recursos desviados, mas também pela consciência de que esses recursos poderiam ter sido investidos em benefícios para os próprios trabalhadores (ITIKAWA, 2006).

Para contrariar tais processos, alguns movimentos sociais têm lutado por mais participação na política. Na última década, as lutas urbanas em São Paulo têm demonstrado uma diversidade de formas de relação e negociação com o Poder Público: ao mesmo tempo que alguns grupos sociais já consolidados negociam em canais institucionalizados, outros recebem uma forma de tratamento antagônica, com repressão violenta e criminalização.

Em relação às/aos trabalhadoras/es ambulantes, os processos de organização delas/es entre 2011-2013 são exemplos emblemáticos de resistência. Em 2012, em um contexto de endurecimento da Prefeitura de São Paulo, de cassação e perseguição das/ os trabalhadoras/es, chegando à proibição total da atividade, houve a constituição de uma rede municipal de trabalhadoras/es, chamada Fórum dos Ambulantes de São Paulo. Esse fórum passou a promover manifestaçóes públicas semanais, protestando contra arbitrariedades nos processos administrativos, falta de diálogo e abusos na fiscalização da atividade (ALCÂNTARA et al., 2013)

Em abril de 2012, na derradeira proibiçáo total de uma atividade de mais de dois séculos, os trabalhadores, articulados com a Defensoria Pública do Estado e com uma ONG de direitos humanos, resolveram interpor uma Ação Civil Pública, fundamentados em uma argumentaçáo inovadora: o direito à cidade. No mesmo mês, o Judiciário paulista concedeu uma liminar autorizando a permanência dos ambulantes em toda a cidade (ITIKAWA, 2015b).

Duas frentes de resistência do Fórum dos Ambulantes aconteceram nos anos 2013 e 2014, com o protagonismo de lideranças mulheres. A primeira foi a participação ativa no processo de elaboraçáo do Plano Diretor de São Paulo. A outra foi o processo de reivindicação para a participação das/os ambulantes nos eventos de São Paulo da Copa do Mundo de 2014. Embora a principal reivindicação das/os trabalhadoras/es fosse a participação na Copa, todo o processo revelou-se excludente: em vez de proibir radicalmente a participação desses trabalhadores na Copa, deixou as condiçôes de trabalho destes, além de informais, precárias e sem autonomia na decisão dos termos da participação. A ação rendeu lucratividade política à prefeitura e lucratividade econômica às empresas patrocinadoras (ITIKAWA, 2015a). O papel da prefeitura na mediação, diluição e conciliação dos conflitos só foi possível com a estratégia, muito eficaz, de dividir o diálogo e negociar, separadamente, com os atores até o ponto em que tudo já estava definido, para, então, no final, terceirizar os detalhes da participação. Não bastasse a precarização dos ambulantes trabalhando na informalidade na Copa, eles tiveram pouca ou nenhuma autonomia decisória em relação aos demais atores. 


\section{MuMBAI: TSUNAMI DE SEGREGAÇÃo E AS ILHAS DE RESISTÊNCIA}

Mumbai é uma metrópole-arquipélago: seu território era composto, anteriormente, de sete ilhas, que se fundiram em uma só península para formar um território geograficamente integrado. Isso se deu graças a uma sucessão de cortes de montanhas para aterros de lagos e canais.

A imagem da fragmentação territorial unida pelo engenho humano para se tornar uma só metrópole não superou as segregaçóes sociais e urbanas. Mumbai tem números superlativos, quando se trata de produção de riqueza, vida urbana diversificada e cosmopolita: maior cidade da Índia em termos populacionais, 21 milhóes de habitantes, e a maior da Ásia em densidade, 20.038 habitantes $/ \mathrm{km}^{2}$, no centro expandido, e 20.925 habitantes $/ \mathrm{km}^{2}$, na periferia; maior Produto Interno Bruto (PIB) do país, concentrando $70 \%$ das transaçóes comerciais e financeiras; possui o porto mais movimentado da Índia; é a capital do entretenimento, possuindo o maior valor do metro quadrado da terra da Índia, etc. Entretanto, de acordo com o censo de 2011, $78 \%$ da população de Mumbai vive em moradias precárias (favelas, cortiços etc.) (GARTENBERG; BHOWMIK, 2014). Em Mumbai, "enquanto os ricos têm 90\% da terra e vivem no conforto em muitas áreas livres, os pobres moram espremidos em $10 \%$ da terra" (DAVIS, 2006). É como se a imensa população pobre se confinasse e se espremesse em ínfimas parcelas do território, em ilhas com altíssima densidade, precariedade na habitação e no acesso às infraestruturas urbanas.

Atualmente, Dharavi - a maior favela da Índia, e a segunda maior do mundo é uma mina de ouro: está estrategicamente ilhada ao redor de um entorno bastante cobiçado. Nos últimos anos, a prefeitura da cidade definiu uma série de intervençóes na favela, uma vez que há uma intensa pressão dos incorporadores de empreendimentos vizinhos e tangentes a Dharavi para a instalação de um distrito de negócios, bem como de condomínios residenciais de classe média e de shoppings na costa leste da cidade (YARDLEY, 2001). Não há a previsão da incorporação plena das atividades econômicas que acontecem no interior de cada um dos domicílios na favela - as reais fontes de geração de renda de seus habitantes, como oficinas domiciliares, armazéns de reciclados, lojas, prestadores de serviço etc. (CARR, 2015).

Dharavi, uma das centenas de favelas de Mumbai, abriga em torno de $1 \mathrm{mi}$ lhão de pessoas e possui a maior concentração de pequenas unidades econômicas informais do mundo. Nela funcionam desde oficinas de trabalho domiciliar e de prestação de serviços a ateliês de cerâmica e centrais de triagem de material reciclável (RISBUD, 2003). Além da incorporação do trabalho infantil na cadeia de produção, sobretudo de meninas, outra violação explícita dos princípios do trabalho decente são as péssimas condiçóes de saúde e de segurança no trabalho (GARTENBERG; BHOWMIK, 2014).

Há uma série de iniciativas de organização advindas das próprias trabalhadoras informais, que contam, ou não, com o apoio de organizaçôes não governamentais, vinculadas a universidades, centros de pesquisa, ordens religiosas e agências multilaterais. Existem mais de $100 \mathrm{ONGs} \mathrm{em} \mathrm{Mumbai} \mathrm{que} \mathrm{dáo} \mathrm{suporte} \mathrm{aos} \mathrm{moradores} \mathrm{de}$ favela na reivindicação de melhores condiçóes de vida (RISBUD, 2003). Em Dharavi, atuam pelo menos três ONGs: Labor Education and Research Network (LEARN), Society for the Promotion of Area Resource Center (SPARC) e Youth for Unity and Voluntary Action (YUVA). Segundo Risbud (2003), alguns políticos também fazem o 
papel de intermediação seletiva de direitos. Para a autora, o clientelismo, além de não prover acesso universal aos direitos sociais, não possibilita ações contínuas e sustentáveis a longo prazo.

Um processo de organização que se iniciou a partir das próprias trabalhadoras domiciliares é o LEARN Mabila Kamgar Sangathana (LMKS). O LMKS foi fundado por Atmadevi Jaiswar, uma trabalhadora domiciliar que articulou mulheres em uma greve a fim de negociar melhores valores pagos por peça de roupa produzida. Atmadevi decidiu reunir um coletivo de trabalhadoras porque os intermediários negociavam valores diferentes por mulher em rúpias indianas: pagavam Rs1,00/peça, Rs1,50/peça ou até Rs2,00/peça. Assim, as mulheres decidiram parar de receber encomendas até que os intermediários pagassem a todas, igualmente, o maior valor negociado na área, isto é, Rs2/peça. O contratante reagiu, recusando o valor, e elas pararam de receber encomendas. $\mathrm{O}$ coletivo náo desistiu. Passados três dias, o contratante, diante do acúmulo de peças náo finalizadas, decidiu aumentar o valor por peça para Rs5,00.

Para Agarwala (2013), há menos consciência de classe operária e mais consciência da exclusão e da exploração. No caso da LMKS, o coletivo se iniciou a partir de laços locais de vizinhança e confiança. Nesse sentido, em geral, a organização das trabalhadoras/es informais se dá por coesão comunitária, não estando claro se o protagonismo delas de fato consegue ter uma amplitude de organização em uma escala territorial (metropolitana ou nacional), com vistas a conquistas de direitos ou de melhoria das políticas públicas. Não foi encontrado um estudo que sistematizasse os movimentos de resistência em Mumbai e o alcance e a sustentabilidade de suas conquistas.

\section{DURBAN: PORTO SEGURO DA DIVISÃO INTERNACIONAL DO TRABALHO E INICIATIVAS À DERIVA}

Durban não foge à regra das cidades sul-africanas: a segmentação e a segregação no mercado de trabalho e na terra são ainda muito marcantes, devido à combinação entre concentração da riqueza e da propriedade: os brancos ainda ocupam os empregos que possuem as melhores remuneraçóes e são beneficiados pela relaçáo favorável entre trabalho formal-moradia-infraestrutura urbana. A segregação territorial originou-se na política do apartheid, cuja legislação definia a exclusão de certas profissóes do mercado de trabalho e da propriedade da terra (CELIK, 2011). Aos negros, em particular, sobravam ocupaçôes como comércio ambulante, trabalho doméstico e domiciliar.

Durban e Johannesburgo são os dois principais centros industriais do país, sendo que o primeiro deles abriga o principal porto nacional (BENNET, 2003; PALMI, 2006). Com a política de abertura de mercado pós-apartheid, a indústria têxtil sul -africana passou a ser uma importante fornecedora de produtos acabados de vestuário para a China e Índia e, ao mesmo tempo, uma importadora de outros itens desses mesmos países.

Em 1999, o governo metropolitano foi pioneiro no país na elaboração da Política Metropolitana da Economia Informal de Durban, que incluía trabalhadoras/es domiciliares, ambulantes e catadoras/es. Foram chamados acadêmicos para a apresentação de estudos que investigassem as dinâmicas econômica e urbana das diferentes cadeias da economia informal. A política teve enfoque urbano, ao determinar que as 
periferias eram os locais prioritários para investimentos do Poder Público, sobretudo os townships (bairros negros), onde a informalidade era maior. (LUND; SKINNER, 1999) A política, finalizada em 2000 e aplicada a partir de 2001, foi considerada, na época do seu lançamento, como um caso exitoso internacional. Ela revelou uma mudança histórica na gestáo governamental, que, deixando de ser assistencialista, passou a dar suporte aos negócios informais.

Em relação às trabalhadoras domiciliares do setor têxtil/vestuário, houve um processo de organização que culminou na formação de um sindicato específico da categoria em 1989, o Sindicato de Trabalhadores Têxteis e do Vestuário Sul-africano (Southern African Clothing and Textile Workers' Union - SACTWU). A SACTWU não faz distinção entre seus filiados, isto é, não importa se eles são formais ou informais, e integra a tradicional central sindical COSATU. Esse sindicato foi decisivo na pressão para a instalação de canais de negociação entre as empresas do setor têxtil/vestuário e as/os trabalhadoras/es informais no início da década de 2000. Outra instituição que atua nos processos de resistência é o Sindicato das Mulheres Trabalhadoras Por Conta Própria (SelfEmployed Women Union - SEWU), exclusivo de mulheres trabalhadoras informais. Ele participou ativamente na elaboração do diagnóstico sobre os aspectos socioeconômicos que subsidiou a Política da Economia Informal de Durban (VALODIA, 2007).

Em relação às trabalhadoras ambulantes, o processo de resistência na metrópole de Durban contra a remoção forçada de trabalhadoras/es da região central para a construção de um shopping foi emblemático do ponto de vista da articulação em rede para negociação coletiva e do protagonismo das mulheres. Esse processo aconteceu durante os preparativos para a Copa do Mundo de 2010 em um local estratégico para a venda ambulante: a Warwick Junction. As trabalhadoras ambulantes da SEWU se aliaram à ONG Asiye Tafuleni, a movimentos sociais e acadêmicos, compondo um movimento de resistência, marcado por protestos e ação judicial. Essa frente teve uma primeira conquista com a vitória, em primeira instância, da açáo judicial contra a expulsão de um mercado na área central. Tal articulação conseguiu a permanência das/os trabalhadoras/es no local; porém, foi iniciada a construção do shopping, que se concluiu exatamente no ano da Copa do Mundo, em 2010, sem a inclusáo, na íntegra, das/os trabalhadoras/es (DOBSON, 2011). Durante a Copa do Mundo na África do Sul, nenhum trabalhador ambulante foi incluído nos projetos de urbanização e construção de infraestrutura para os jogos, apesar da intensa campanha dos movimentos sociais e da própria SEWU (CELIK, 2011).

\section{CONCLUSÃO: DESMATERIALIZAR OS BRAÇOS PARA TOMAR A TERRA}

\section{A PERIFERIA COMPULSÓRIA}

Apesar das recentes transformaçôes na economia e mobilidade urbanas, não houve um rompimento com a lógica da segregação socioespacial e da expansão urbana predatória em direção às periferias, marcada por assentamentos informais e sem infraestrutura adequada, por moradia sem titularidade e pela oferta insuficiente ou precária de oportunidades ocupacionais.

Por essas razóes, pode-se afirmar que as/os trabalhadoras/es informais têm con- 
diçóes desiguais de acesso aos e permanência nos mercados de trabalho. A autonomia delas/es é desarticulada, porque, embora tenham independência laboral, não possuem a contrapartida da soberania para definir os termos de troca. Além da falta de autonomia decisória, ainda enfrentam a expulsão compulsória do espaço urbano e a desarticulação das dinâmicas produtivas, da organização e luta de classes e da participaçáo no regime de acumulaçáo capitalista.

As políticas de formalização e empreendedorismo não consideram o protagonismo coletivo das/os trabalhadoras/es. Os exemplos citados evidenciam que, apesar da posição preponderante do Estado a favor do avanço dos direitos, há uma série de problemas e desafios no diálogo social. Nesse sentido, resta às/aos trabalhadoras/ es informais a periferia compulsória, um território à margem do acesso à terra e ao trabalho formal e do diálogo social, normalmente restrito, pontual e discricionário.

\section{RESERVA DE BRAÇOS E DE TERRAS: SUBACUMULAÇÃo E SUPERACUMULAÇÃo}

A informalidade subordinada e a autonomia desarticulada são duas faces da mesma moeda: não há neutralidade na posição que os trabalhadores informais ocupam na periferia do capitalismo. Nesse sentido, é impossível dizer que haverá a transição automática do informal para o formal, uma vez que a informalidade funciona como reserva de braços e terras por subacumulação e superacumulação.

Subacumulação, porque tanto no trabalho subcontratado quanto no trabalho por conta própria são extraídos os direitos trabalhistas e todo o aparato social de reprodução social da força de trabalho. Além de a informalidade servir apenas para sobrevivência dos trabalhadores (ou alimentar outras sobrevivências, como vimos), estes não estão incluídos no sistema de proteção social e de acesso formal aos demais direitos sociais, como habitação, saneamento, transporte etc.

Superacumulação, porque as demonstraçóes de despossessão (HARVEY, 2005) para superacúmulo do capital por extração da mais-valia acontece a partir da superexploração do trabalho: baixíssima remuneração por peça, longas jornadas de trabalho, formas diferentes de controle sobre o tempo e a produção etc. A superexploração do trabalho acontece porque há uma clara assimetria decisória como reflexo de relaçóes desiguais de poder e de subordinação. Para as mulheres, há ainda outra camada de superacumulação, pois recaem sobre elas os trabalhos produtivo e reprodutivo não remunerados e desprotegidos.

Para maquiar a informalidade por meio da formalizaçáo de microempreendedores, o capital criou o revés do microempreendedorismo: a fraude das relaçôes de subordinação, na medida em que são utilizadas a retirada de direitos trabalhistas como expedientes de empresas para evitar a necessidade de cumprir certos deveres. A substituição de contratos de trabalho por contratos de prestação de serviço é largamente praticada como uma forma de sanear cadeias inteiras de produção, livrando as empresas dos direitos trabalhistas e, logo, precarizando o trabalho.

A reserva de braços e de terras para futura apropriação é, portanto, funcional à reproduçáo do capitalismo na periferia. As terras ocupadas por favelas, quando são alçadas ao interesse do mercado imobiliário, tornam-se automaticamente territórios a serem tomados a um preço barato para futura produção imobiliária. Os braços de trabalhadoras/es informais, da mesma forma, como excedente da força de trabalho, 
atuam exercendo forte pressão no rebaixamento dos salários, na rotatividade do emprego formal, na extração dos direitos trabalhistas e na redução do custo de trabalho.

\section{BANQUETE PARA POUCOS}

Os regimes excludentes, sobretudo no acesso à terra e ao emprego urbanos, têm sido decisivos para a manutenção de uma cidadania racionada. Marfaing e Thiel (2015) falam em redes de acumulação e em redes de sobrevivência; eles mostram os operadores que orbitam em torno dessas redes para a mediaçáo e ponte aos direitos. Trata-se de uma participaçáo seletiva na riqueza, combinada a estratégias de rebaixamento dos custos da terra e da moradia. Se, por um lado, é possível dizer que há redes de suporte que fazem o trabalho de politizaçáo e fortalecimento das/os trabalhadoras/es no sentido de alavancar a representatividade delas/es; por outro, esse esforço não tem resultado na universalização dos direitos. A mediação de direitos, seja pelo clientelismo, seja por ação de ONGs, acaba sendo pontual e discricionária. As fronteiras entre apoio, suporte, intermediação ou tutela são muito imprecisas. A pesquisa bibliográfica a respeito das três metrópoles apontou que algumas dessas açôes recaem na dependência mútua.

\section{MULHERES INSUBORDINADAS}

A revisão da literatura sobre os três países, as entrevistas realizadas em São Paulo e o grupo focal conduzido em Mumbai mostraram várias nuances de subordinação. Contudo, os exemplos de insubordinação coletivos, ainda que pareçam desarticulados, são tão pungentes quanto os esforços para aniquilá-los. É certo que as políticas macroeconômicas, a herança colonial, a segregação e a discriminação nativas e a divisão internacional do trabalho resultaram em informalidade, subordinação e desarticulação das/os trabalhadoras/es informais. Por sua parte, a articulação em rede, os protestos e as açóes judiciais são exemplos de processos de resistência que têm desafiado a exclusão, a periferia e a subordinação compulsória.

Não há um mesmo cálculo entre os países que possa resultar no avanço dos processos de resistência contra a gestáo da exceção. Cada um dos casos examinados avançou em frentes específicas. Todavia, em conjunto, as falas das trabalhadoras informais entrevistadas carregam o mesmo tom dos dizeres de uma trabalhadora ambulante de Jabaquara, periferia sul de São Paulo: "nós mulheres somos maioria na exclusão. Já perdi muita coisa nessa vida, e agora tô ganhando. Agora que eu comecei, não vou mais parar".

\section{REFERÊNCIAS BIBLIOGRÁFICAS}

ABÍLIO, L.C. O Make up do trabalho: uma empresa e um milhão de revendedoras de cosméticos. 2011. Tese (Doutorado em Ciências Sociais) - Instituto de Filosofia e Ciências Humanas, Universidade Estadual de Campinas, Campinas, 2011.

ABRAMO, L. A Inserção da mulher no mercado de trabalho no Brasil: uma força secundária? 2007. Tese (Doutorado em Sociologia) - Faculdade de Filosofia, Letras e Ciências Humanas, Universidade de São Paulo, Sáo Paulo, 2007.
Luciana Fukimoto Itikawa é doutora em Arquitetura e Urbanismo pela Faculdade de Arquitetura e Urbanismo da Universidade de São Paulo (FAU/USP); pós-doutoranda no Instituto de Estudos Brasileiros (IEB) da USP.

E-mail: luciana.itikawa@ gmail.com.

Artigo recebido em 13 de setembro de 2015 e aprovado para publicação em 9 de abril de 2016. 
AGARWALA, R. Informal Labor, formal politics, and dignified discontent in India. New York: Cambridge University Press, 2013.

ALCÂNTARA, A. et al., Ambulantes e Direito à Cidade. Trajetórias de vida, organização e políticas públicas. São Paulo: CGGDH, 2013.

BARBOSA, A. F. A formação do mercado de trabalho no Brasil. São Paulo: Alameda Casa Editorial, 2008.

et al. Project paper Comparative C. In: CEBRAP; UNIVERSIDADE DE SÃO

PAULO; IHD NEW DELHI. Growth Regimes, Labor Markets and Inequality in Brazil and India: Parallel Experiences in Historical Perspective. March 7 $7^{\text {th }}, 2015$.

BENNET, M. Organizing in the informal economy: a case study of the Clothing Industry in South Africa. Geneva: International Labor Office, 2003.

BHORAT, H. et al. Labor market and social welfare outcomes in the context of crisis. In: BARBOSA, A. F.; CACCIAMALI, M. (Org.). The "Dynamic South", economic development and inclusive growth: the challenges ahead. São Paulo: CEBRAP, 2013. p. 137-185.

BÓGUS, L. M. M.; TASCHNER, S. P. São Paulo, velhas desigualdades, novas configurações espaciais. Revista Brasileira de Estudos Urbanos Regionais, Sáo Paulo, n. 1, p. 153-174, maio 1999.

CACCIAMALI, M. C. Causes and Interpretations of Social Inequalities. In: INSTITUTE FOR HUMAN DEVELOPMENT; CENTRO BRASILEIRO ANÁLISE PLANEJAMENTO. Labor Market Inequality in Brazil and India: Concepts and Methods of Analysis. São Paulo: CEBRAP; Nova Delhi: IHD, 2014.

CARR, C. The best idea to redevelop Dharavi slum? Scrap the plans and start again. The Guardian, 18 fev. 2015. Disponível em: <https://www.theguardian.com/cities/2015/ feb/18/best-ideas-redevelop-dharavi-slum-developers-india $>$. Acesso em: 20 jan. 2016.

CELIK, E. The exclusion of street traders form the benefits of the FIFA 2010 World Cup in South Africa. African Journal of Business and Economic Research, Durban, v. 6, n. 1, p. 62-86, mar. 2011.

CGGDH, Trabalho Informal e Direito à Cidade: Dossiê de Violaçôes de Direitos de trabalhadores ambulantes e domiciliares imigrantes. São Paulo: CGGDH, 2012.

CHEN, M.; RAVEENDRAN, M. Urban Employment in India: Recent Trends and Patterns. Cambridge: WIEGO, 2014 (WIEGO Working Paper, 7).

DAVIS, M. Planeta Favela. São Paulo: Boitempo Editorial, 2006.

DOBSON, R. Saving the Mother Market: Mobilizing Street vendors in Durban. Inclusive Cities report, ago 2011. Disponível em: <http://www.inclusivecities.org/wp-content/ uploads/2012/07/Dobson_Success_Story_Saving_Mother_Market.pdf $>$. Acesso em: 20 abr. 2016.

FREYRE, G. Casa Grande e Senzala. São Paulo: Atual, 1997.

GARTENBERG, I.; BHOWMIK, S. Organizing the unorganized: Mumbai's homeworkers lead the way. Mumbai: Labor Education and Research Network, 2014. Disponível em: <http://learn-india.org/>. Acesso em: 20 abr. 2016.

HARVEY, D. O "novo imperialismo": ajustes espaço-temporais e acumulação por desapossamento. Lutas Sociais, São Paulo, n. 13/14, p. 9-21, 2005.

INSTITUTO BRASILEIRO DE GEOGRAFAI E ESTATÍSTICA (IBGE). SIS 2014: Em nove anos aumenta a escolaridade e o ensino superior. Sala de Imprensa IBGE, Rio de Janeiro, 17 dez. 2014. Disponível em: <http://saladeimprensa.ibge.gov.br/noticias?view=noticia\&id=1\&busca=1\&idnoticia=2796>. Acesso em: 20 jan. 2016.

INTERNATIONAL LABOUR OFFICE (ILO). The transition from the informal to the formal economy. International Labour Conference 104th Session, 2015. Genebra: ILO, 2015.

ITIKAWA, L. Vulnerabilidades do Trabalho Informal de Rua: Violência, corrupção e clientelismo. São Paulo em Perspectiva, São Paulo, v. 20, n. 1, p. 136-147, jan./mar. 2006. 
Terceirização e o rapto do Território do Trabalho. Grupo de Pesquisa Trabalho e Capital, São Paulo, 13 abr. 2015a. Disponível em: <https://grupodepesquisatrabalhoecapital.wordpress.com/2015/04/13/terceirizacao-e-o-rapto-do-territorio-dotrabalho/>. Acesso em: 20 jan. 2016.

Ambulantes na Copa: a formula mágica da participação excludente: por trás do monopólio da exploração, a conciliação e a subordinação. In: COMITÊ POPULAR DA COPA DE SÃO PAULO. Copa pra Quem? A Copa do Mundo FIFA 2014 numa perspectiva abaixo e à esquerda. São Paulo: CPCopa SP, 2015 b.

KREIN, J. D. Tendências recentes nas relaçóes de Emprego no Brasil: 1990-2005. 2006 Tese (Doutorado em Desenvolvimento Econômico) - Instituto de Economia, Universidade Estadual de Campinas, Campinas, 2006.

LUND, F.; SKINNER, C. Promoting the interests of women in the informal economy: an analysis of street trader organizations in South Africa. Durban: CSDS, ago 1999 (CSDS Research Report, 19).

MARFAING, L.; THIEL, A. Networks, spheres of Influence and the mediation of Opportunity: the Case of West African Trade Agents in China. The journal of Pan African Studies, Sun Village, v. 7, n. 10, p. 65-84, maio 2015.

MARICATO, E. A Metrópole na Periferia do Capitalismo. São Paulo: FAU/USP, 1995. Disponível em: <http://fau.usp.br/depprojeto/labhab/biblioteca/textos/maricato_metrperif. pdf>. Acesso em: 20 jan. 2016.

. Habitação e Cidade. São Paulo: Atual, 1997.

MARQUES, E. (Org.). A Metrópole de São Paulo no início do século XXI. São Paulo: Ed. Unesp, 2015.

MISSE, M. Rio como um bazar: a conversão da ilegalidade como mercadoria política. Insight Inteligência, Rio de Janeiro, v. 3, n, 5, p. 12-16, 2002. Disponível em: <http://necvu. tempsite.ws/images/2oriocomoumbazar.pdf>. Acesso em: 20 jan. 2016.

OLIVEIRA. F. Crítica à razão dualista/O Ornitorrinco. São Paulo: Boitempo Editorial, 2003.

PALMI, R. Stitching for Survival: home-based clothing operations in the informal economy. The experience of two women in Kwazulu Natal South Africa. Durban: School of Development Studies, University of Kwazulu Natal, 2006.

PAMPLONA, J.B. Mercado de trabalho, informalidade e comércio ambulante em São Paulo. Rev.Bras. Estudos Populacionais, Rio de Janeiro, v. 30, n.1, p. 225-249, jan/jun. 2013.

POCHMANN, M. O Emprego no desenvolvimento da Nação. São Paulo: Boitempo Editorial, 2008.

PYL, B. Trabalho escravo abastece produção da marca Talita Kume. Repórter Brasil, São Paulo, 11 jul. 2012. Disponível em: <http://reporterbrasil.org.br/2012/07/trabalho-escravo-abastece-producao-da-marca-talita-kume/>. Acesso em: 20 jan. 2016.

; HASHIZUME, M. Escravizados produziram coletes de recenseadores do IBGE. Repórter Brasil, São Paulo, 20 out. 2010. Disponível em: <http://reporterbrasil.org. br/2010/10/escravizados-produziram-coletes-de-recenseadores-do-ibge/>. Acesso em: 20 jan. 2016.

RACE in South Africa: still an issue. The Economist, Cape Town, 4 fev. 2012. Disponível em: $<$ http//www.economist.com/node/21546062>. Acesso em: 20 jan. 2016.

RISBUD, N. Urban slums reports. The Case of Mumbai, India. Londres: University College London, 2003. Disponível em: <http:/www.ucl.ac.uk/dpu-projects/Global_Report/ pdfs/Mumbai.pdf>. Acesso em: 20 jan. 2016.

ROLNIK, R. A Guerra dos Lugares. São Paulo: Boitempo Editorial, 2015.

SCHWARZ, R. Martinha versus Lucrécia. São Paulo: Companhia das Letras, 2012.

SKINNER, C. Challenging City Imaginaries: Street traders' struggles in Warwick Junction. Agenda, Durban, v. 81, jan. 2009. 
TAVARES, M. C.; FIORI, J. L. (Des)ajuste global e modernização conservadora. São Paulo: Paz e Terra, 1993.

TELLES, V. S. Mutaçóes do Trabalho e experiência urbana. Tempo Social, São Paulo, v. 18, n. 1, p. 173-195, jun. 2006.

UNNI, J. Are Gender differentials in educational capabilities mediated through institutions of caste and religion in India? Ahmedabad: Gujarat Institute of Development Research, set. 2008 (Working Paper, 86).

VALODIA, I. The Informal Economy in South Africa: issues, debates and policies. Reflections after an exposure dialogue programme with informal workers in Durban, South Africa. Durban: School of Development Studies, University of KwaZulu-Natal, mar. 2007 (Research Report, 75).

YARDLEY, J. In one slum, misery, work, politics and hope. The New York Times, Nova Iorque, 28 dez. 2011. Disponível em: <http://www.nytimes.com/2011/12/29/world/ asia/in-indian-slum-misery-work-politics-and-hope.html?_r=0>. Acesso em: 20 jan. 2016.

YU, D. Defining and Measuring Informal Employment in South Africa: a Review of Recent Approaches. Johannesburg: DPRU, 2010. Disponível em: <http://wiego.org/sites/ wiego.org/files/publications/files/Yu_Informal\%20Employment\%20-\%20Yu.pdf>. Acesso em: 20 jan. 2016. 